\title{
Reavaliação paleoambiental e estratigráfica da Formação Nobres do Grupo Araras, Neoproterozóico da Faixa Paraguai, região de Cáceres (MT)
}

\author{
Isaac Daniel Rudnitzki ${ }^{1 *}$, Afonso Cesar Rodrigues Nogueira ${ }^{1}$
}

\begin{abstract}
Resumo A Formação Nobres representa a última deposição carbonática neoproterozoica do Grupo Araras, na porção sudoeste da Faixa Paraguai Norte. Estudos faciológicos e estratigráficos em afloramentos na região de Cáceres, no estado do Mato Grosso, subdividiram a Formação Nobres em: membro inferior, composto de dolomitos finos, dolopackstones intraclásticos, dolomitos arenosos, estromatólitos estratiformes e moldes evaporíticos, interpretados como depósitos de planície de maré/sabkha; e membro superior, composto por dolomitos finos, arenitos dolomíticos, estromatólitos estratiformes a dômicos e rugosos e moldes evaporíticos, além de arenitos e pelitos interpretados como depósitos de planície de maré mista. O empilhamento destes depósitos de até $200 \mathrm{~m}$ de espessura é composto por ciclos métricos de raseamento/salinidade ascendente relacionado a um clima árido. Os ciclos de perimaré também sugerem geração contínua e recorrente de espaço de acomodação provavelmente ligado à subsidência tectônica. O influxo de sedimentos siliciclásticos no final da deposição da Formação Nobres inibiu a sedimentação carbonática e é atribuída ao soerguimento de áreas-fontes ligado ao início do fechamento do Oceano Clymene, durante a colisão Pampeana-Araguaia, no limite Neoproterozoico-Cambriano.
\end{abstract}

Palavras-chave: análise de fácies; Neoproterozoico; Formação Nobres; Grupo Araras.

\begin{abstract}
The Nobres Formation represents the last Neoproterozoic carbonate deposition of the Araras Group in the southwestern part of the Northern Paraguay Belt. Outcrop-based facies and stratigraphic studies in the region of Cáceres, State of Mato Grosso, Brazil, subdivided the Nobres Formation into: lower member, composed of dolostone, intraclastic dolopackstones, sandy dolostones, stratiform stromatolites and evaporitic molds, interpreted as tidal flat/sabkha deposits; and upper member, constituted of dolostone, dolomitic sandstone, stratiform to domal and wrinkled stromatolites, evaporite molds, sandstones and mudstones, interpreted as mixed tidal flat deposits. The stacking of these deposits up to $200 \mathrm{~m}$ thick is composed by meter-thick shallowing/brining upward cycles related to a hot arid climate. The peritidal cycles also suggest continuous and recurrent generation of accommodation linked to tectonic subsidence. The siliciclastic inflow at the end of the deposition of the Nobres Formation that hindered the carbonate sedimentation and is attributed to the uplift of source areas linked to the initial phase of closure of the Clymene Ocean, during the Pampean-Araguaia Orogeny, at the limit Neoproterozoic-Cambrian.
\end{abstract}

Keywords: facies analysis; Neoproterozoic; Nobres Formation; Araras Group.

INTRODUÇÃO A sucessão carbonática do Grupo Araras, aflorante na Faixa Paraguai Norte, região central do Brasil, guarda importantes registros de episódios decorrentes do final do Neoproterozoico, como a capa carbonática depositada após o último evento de glaciação global Criogeniana, relacionada à hipótese do snowball/slushball Earth (Hoffman \& Schrag 2002, Nogueira \& Riccomini 2006, Nogueira et al. 2007, Soares \& Nogueira 2008).

A Faixa Paraguai foi formada durante o evento orogenético Brasiliano/Pan-Africano, finalizado na transição do Neoproterozoico-Cambriano (Almeida 1984, Trompette 1997). Neste período, houve o fechamento do Oceano Clymene, cuja margem passiva é caracterizada principalmente pela sedimentação carbonática plataformal do Grupo Araras
(Tohver et al. 2009), sucedida pelos depósitos siliciclásticos do Grupo Alto Paraguai (Fig. 1A). Na transição dos depósitos carbonáticos para os siliciclásticos ocorrem depósitos mistos da Formação Nobres, que representa a última sedimentação carbonática do Grupo Araras. A Formação Nobres, na região de Cáceres (MT), objeto deste estudo, faz parte da porção norte da Faixa Paraguai e está exposta em flancos de dobras observadas na pedreira Emal-Camil e cortes de estrada da Rodovia BR-070, nos kms 678 e 693 (Fig. 1B). Este trabalho apresenta os resultados de estudos faciológicos e estratigráficos que permitiram detalhar as exposições descritas por Nogueira \& Riccomini (2006), no âmbito paleoambiental e estratigráfico da Formação Nobres.

\footnotetext{
${ }^{1}$ Universidade Federal do Pará - UFPA, Belém (PA), Brasil. E-mails: rudnitzki@ufpa.br, anogueira@ufpa.br

*Autor correspondente
} 
ASPECTOS GEOLÓGICOS A Faixa Paraguai, entidade tectônica neoproterozoica inserida na Província Tocantins, foi estruturada durante o evento orogenético Brasiliano/ Pan-Africano, entre $600 \mathrm{e}$ 540 milhões de anos (Ma) (Almeida 1984, Trompette 1997). É resultante da convergência e colisão de três blocos continentais: ao oeste, o Amazônico; ao leste, o São Francisco-Congo; e ao sul, o Paraná ou Rio de la Plata, sendo o último recoberto pelos depósitos fanerozoicos da Bacia do Paraná. A Faixa Paraguai tem diferentes propostas de subdivisão tectônica (Almeida 1964, Almeida 1984, Alvarenga \& Trompette 1994, Nogueira et al. 2007). Em geral dois domínios estruturais podem ser discriminados de oeste para leste: um interno, não deformado a pouco deformado, onde estratos preenchem duas sub-bacias foredeep na margem; e um externo, no qual dobras e falhas cavalgantes afetam rochas carbonáticas e siliciclásticas dos grupos Araras e Alto Paraguai. A área estudada encontra-se na porção Sudoeste do domínio externo (Fig. 1A). A Faixa Paraguai é limitada ao Norte e Noroeste pelas rochas do embasamento cristalino e sedimentos da Bacia do Parecis, e ao Sul e Sudoeste pelos depósitos quaternários (Fig. 1B). As rochas metassedimentares do Grupo Cuiabá, aflorantes na porção Sudeste e Leste da faixa, representam seus depósitos mais antigos, sendo intrudidos
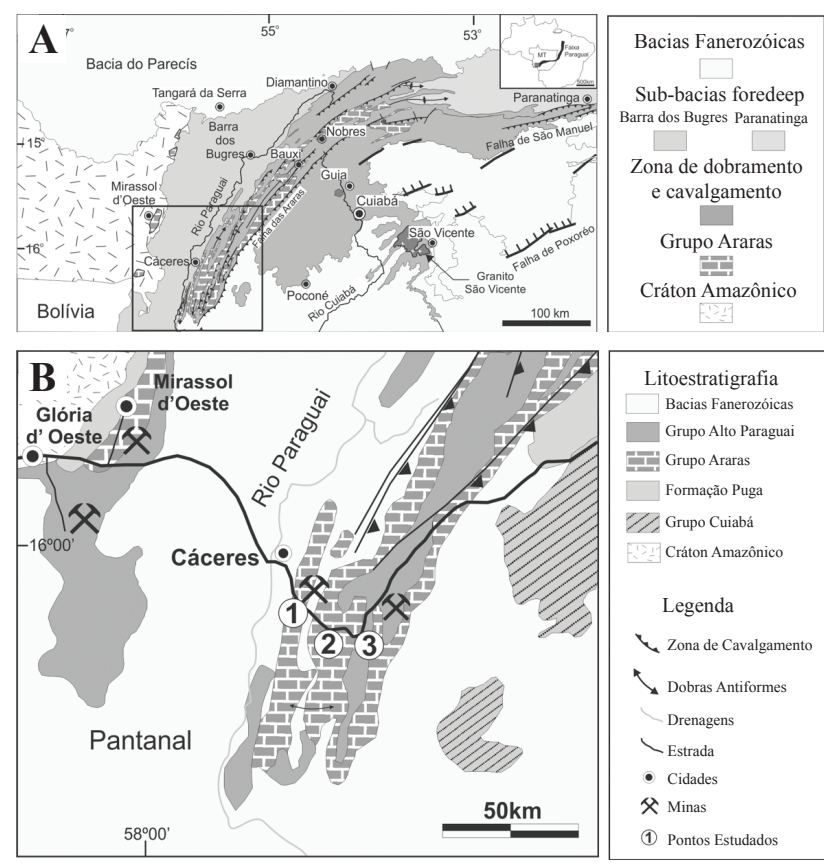

Mapa de localização da área de estudo e perfis estudados

Figura 1 - (A) Divisão tectônica segundo Nogueira et al. (2007); (B) Mapa geológico da região de Cáceres (MT) - (1) Pedreira Emal/Camil; (2) km 678 da BR-070; (3) km 693 da BR-070. pelo Granito São Vicente de $\sim 500$ Ma (Almeida \& Mantovani 1975), o que sugere a idade mínima para a sucessão sedimentar da Faixa Paraguai.

As rochas carbonáticas da Faixa Paraguai foram reportadas por outros trabalhos antes de serem elevadas à categoria de grupo (Castelneau 1850, Evans 1894). A definição do Grupo Araras foi feita por Almeida (1964), que individualizou uma unidade inferior de calcários argilosos e uma superior de dolomitos. Baseado nesta proposta, Hennies (1966) denominou a unidade inferior como Formação Guia e a superior como Formação Nobres. Estudos posteriores propuseram outras categorias estratigráficas para sucessão de rochas carbonáticas (Figueiredo \& Olivatti 1974, Barros et al. 1982, Boggiani 1997), no entanto não foi feita formalização adequada e consensual dos termos litoestratigráficos. Com base em análise de fácies e estratigráfica, Nogueira \& Riccomini (2006) e Nogueira et al. (2007) subdividiram o Grupo Araras nas formações: Mirassol d'Oeste, Guia, Serra do Quilombo e Nobres (Fig. 2). Este grupo de rochas recobre os diamictitos glaciais da Formação Puga e, por sua vez, está recoberto pelas rochas siliciclásticas do Grupo Alto Paraguai ou, segundo Alvarenga et al. (2007), pelos siltitos e diamictitos glaciogênicos da Formação Serra Azul. Idades radiométricas obtidas por meio da razão de chumbo por chumbo $(\mathrm{Pb} / \mathrm{Pb})$ na base do Grupo Araras revelam idades de $627 \mathrm{Ma} \pm 30$ (Babinsky et al. 2006), o que

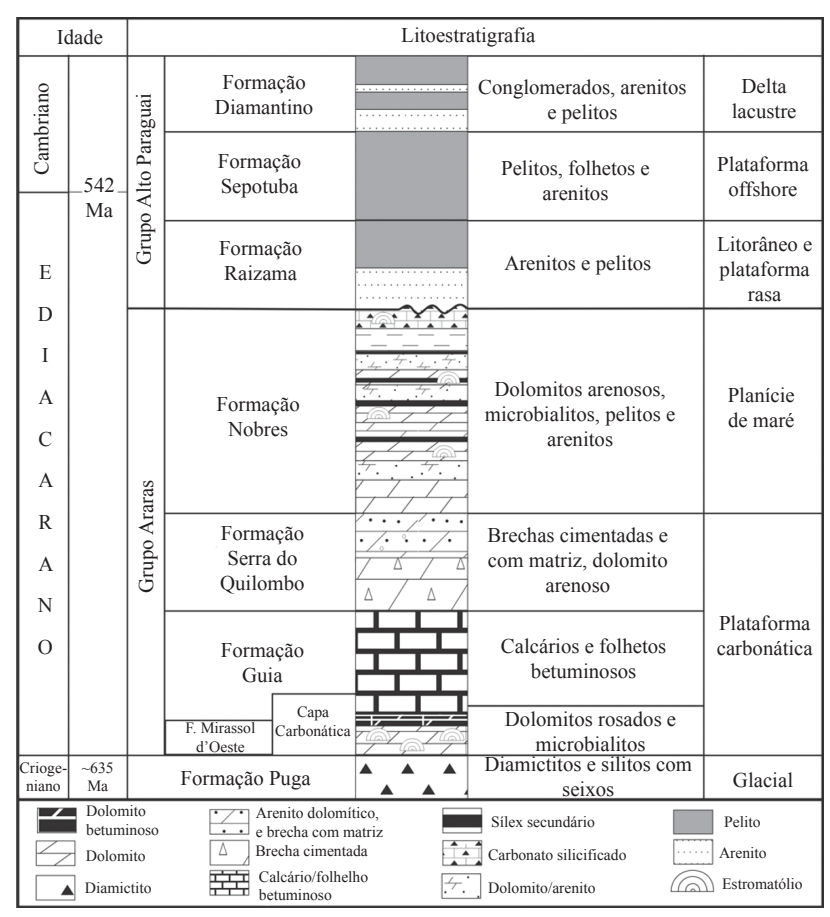

Figura 2 - Proposta da coluna estratigráfica do Grupo Araras (modificado de Nogueira \& Riccomini 2006). 
suporta a correlação quimioestratigráfica de isótopos de carbono após a última glaciação Cryogeniana (Marinoana) de 635 Ma (Nogueira 2003, Alvarenga et al. 2004, Halverson et al. 2004, Nogueira et al. 2007), encontrada em sucessões neoproterozoicas de várias partes do mundo interpretada como um evento de precipitação sincrônico após a glaciação global.

A Formação Nobres foi primeiramente formalizada por Hennies (1966), ao nomear os carbonatos dolomíticos da parte superior do Grupo Araras. Nogueira \& Riccomini (2006) reconheceram que a unidade ocorre por cerca de $300 \mathrm{~km}$ de extensão na parte norte da Faixa Paraguai e forma ciclos métricos tabulares, lateralmente contínuos por centenas de metros. O limite inferior da Formação Nobres é com os dolomitos da Formação Serra do Quilombo na forma de contato irregular, e o limite superior, com as rochas siliciclásticas da Formação Raizama do Grupo Alto Paraguai, representa um contato erosivo. A Formação Nobres é interpretada como sucessão de arrasamento e salinização ascendentes. Na base, os ciclos são relacionados a um ambiente de inframaré (dolomito fino maciço a laminado) e intermaré/ supramaré/sabkha (ritmito dolomito/dolomito arenoso), enquanto os ciclos do topo são atribuídos à planície de maré e intermaré de clima árido (dolomito fino, dolomito arenoso, arenito dolomítico e pelitos).

MÉTODOS O método de estudo das fácies sedimentares segue as propostas de Walker (1992) e Kerans \& Tinker (1997), com o intuito de integrar e complementar ambos os métodos de individualização e interpretação de fácies sedimentares. Uma análise petrográfica foi empregada com o objetivo de classificar as rochas segundo Dunham (1962), além de auxiliar a interpretação paleoambiental e verificar o grau de influência dos processos diagenéticos segundo a proposta de Tucker (1992). As lâminas foram confeccionadas de amostras sistematicamente coletadas em função das variações faciológicas e tingidas com alizarina vermelha-S para discriminação entre calcita e dolomita (Adams et al. 1984).

\section{FORMAÇÃO NOBRES}

\section{Aspectos gerais e base de dados}

A Formação

Nobres ocorre geralmente em flancos de dobras com mergulho de até $45^{\circ}$ para NW ou SW. É composta por dolomitos microcristalinos, rochas mistas (composição carbonática e siliciclástica), arenitos finos a médios e pelitos. As rochas apresentam camadas tabulares e coloração cinza escuro e, quando intemperizadas, exibem tons amarelados e esbranquiçados. São comuns feições diagenéticas de dolomitização (dolomito grosso), estilólitos e silicificação. Zonas silicificadas, geralmente de coloração cinza escura, marcam limites de camada e substituem total ou parcialmente os carbonatos, tendo a maior preferência em níveis de estromatólitos, destacando localmente a laminação microbiana. Processos de tripolitização são indicados pelo aspecto pulverulento dos níveis silicificados.

Os estudos dos afloramentos da Formação Nobres na região de Cáceres permitiram a confecção de três perfis estratigráficos, cuja composição resultou na espessura $200 \mathrm{~m}$ da unidade (Figs. 3 e 4). O limite inferior da Formação Nobres se faz com a Formação Serra do Quilombo. As fácies no topo da Formação Serra do Quilombo compõem ciclos de raseamento ascendente com até $10 \mathrm{~m}$ de espessura, formados por dolomitos finos laminados que são recobertos por dolopackstone oolíticos com acamamento maciço, estratificações cruzadas swaley e de baixo ângulo, bem como laminação truncada por ondas, interpretados como depósitos de shoreface influenciada por ondas e tempestades (Nogueira \& Riccomini 2006) (Figs. 3 e 5B).

A base da Formação Nobres é composta por ciclos de raseamento ascendente de até $6 \mathrm{~m}$ de espessura, formados por dolomito fino maciço recoberto por dolopackstone intraclástico interpretados como ciclos de perimaré. $\mathrm{O}$ limite entre as formações é brusco, sendo caracterizado por um nível de brecha carbonática maciça, com matriz de até $2,5 \mathrm{~m}$ de espessura. Ela consiste em dolomito fino que envolve clastos tabulares a subarredondados de dolomito fino (Figs. 3 e 5A). Embora a passagem seja brusca (brecha dolomítica $\mathrm{x}$ dolomito fino), a litologia ainda permanece como carbonática, e a ciclicidade, que inclui depósitos de shoreface (Serra do Quilombo), passa para ciclos de perimaré (Nobres) em uma transição de fácies sem interrupção na sedimentação (Fig. 3). O limite superior da Formação Nobres é com as rochas siliciclásticas do Grupo Alto Paraguai, mais especificamente com a Formação Raizama, sendo caracterizado por uma discordância erosiva marcada por conglomerados com clastos de arenito fino e carbonato (Figs. 3 e 5C). A Formação Raizama é composta por arenito médio a grosso e pelito, com estratificações cruzadas acanalada e mud drapes (Fig. 5D), e estratificação plano-paralela, que constitui ciclos 


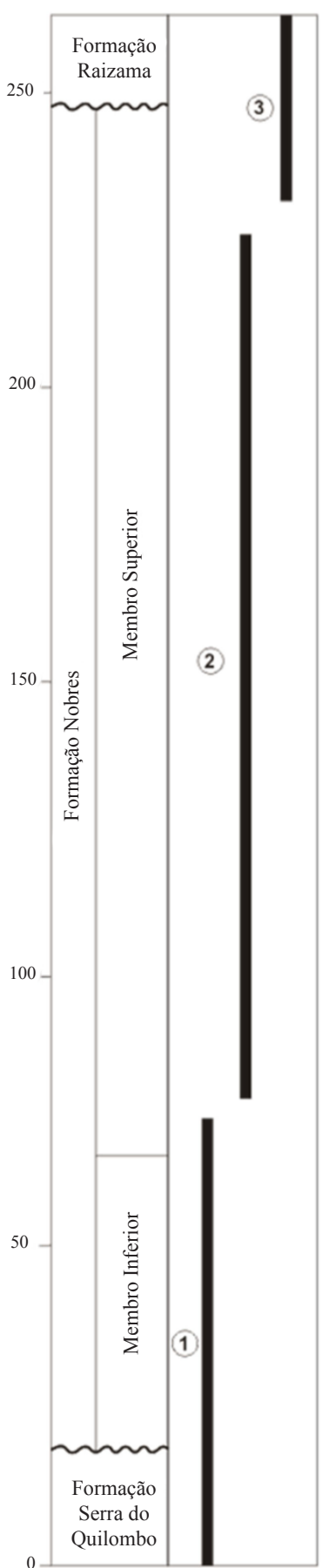

LEGENDA

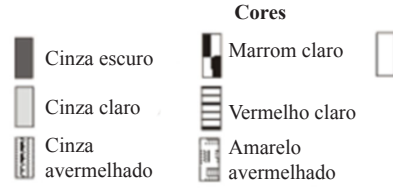

\section{Litologia}

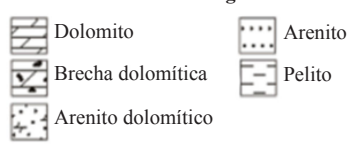

$$
\text { :- Arenito dolomítico }
$$

Siliciclásticos

$$
\text { Carbonatos }
$$

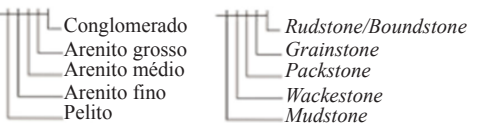

250

250

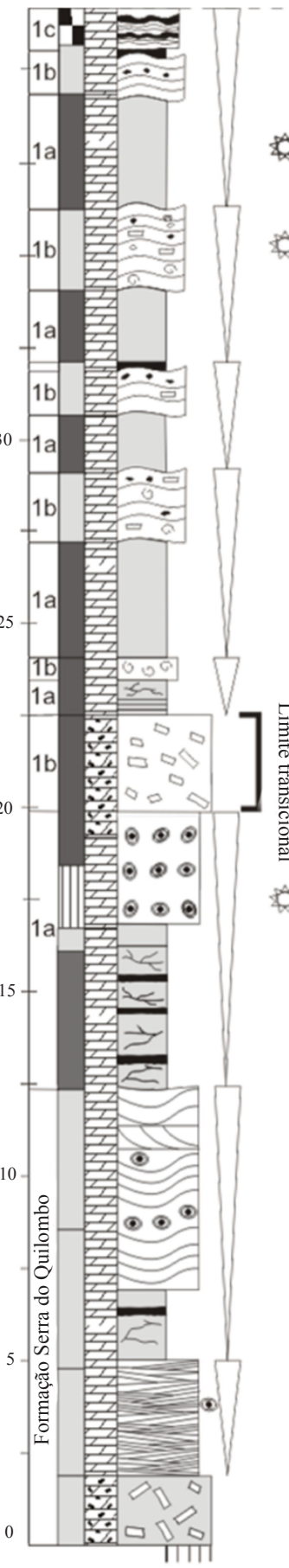

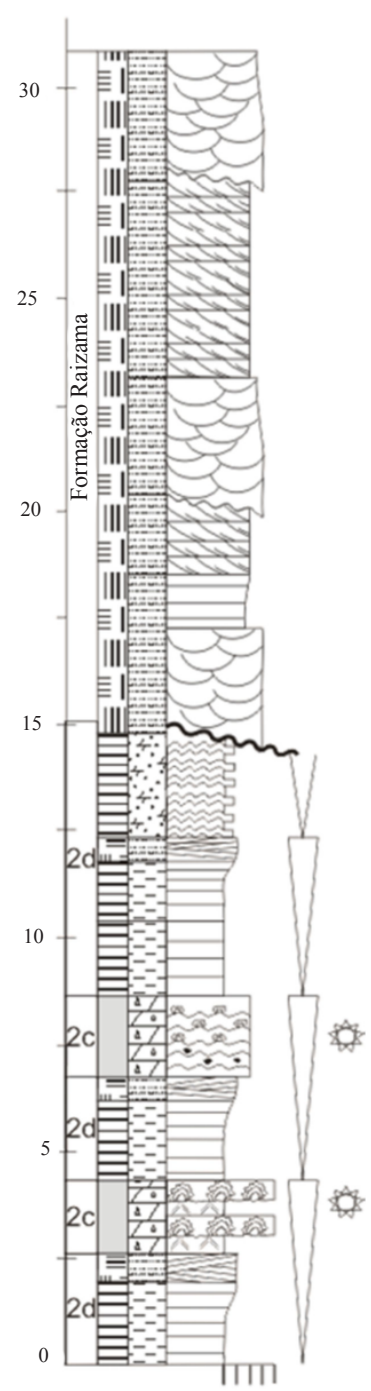

Estruturas

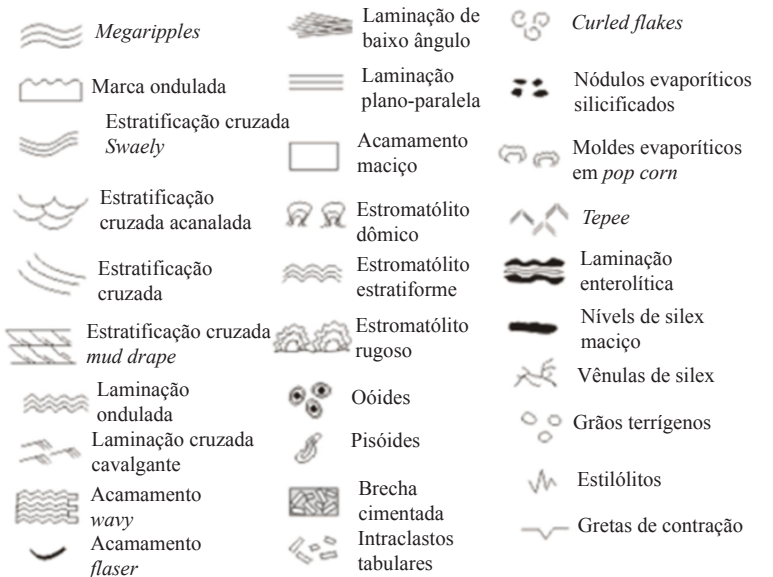

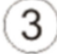

3

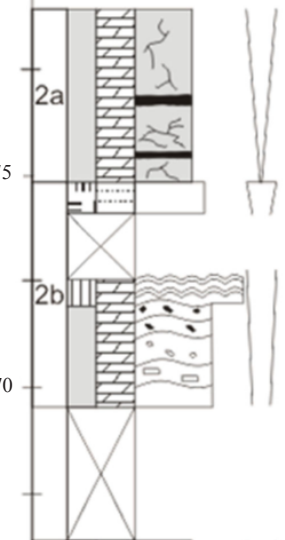

65

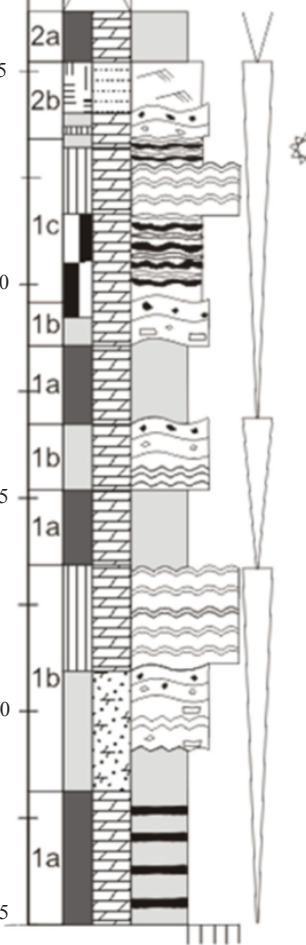

Associação de Fácies Sedimentares

AF1 - Planície de maré/Sabkha

1a - Inframaré

$1 \mathrm{~b}$ - Intermaré

1c - Supramaré/Sabkha

AF2 - Planície de maré árida mista

2a - Inframaré

$2 \mathrm{~b}$ - Intermaré mista

c - Supramaré

2d - Inframaré/Intermaré siliciclástica

Ciclos e Limites Estratigráficos

Limite estratigráfico

discordante

Ciclos de

raseamento/salinidade

ascendente

8 Amostras

Figura 3 - Perfis estratigráficos da Formação Nobres. Seção 1: Pedreira Emal-Camil; Seção 3: km 693 da Rodovia BR-070. 
granodecrescentes ascendentes e interpretados como sistema de estuarino siliciclástico (Nogueira \& Riccomini 2006, Silva Júnior et al. 2007).

A partir dos dados obtidos, a Formação Nobres foi subdividida em dois membros: inferior, constituído por dolomito fino, dolopackstone/wackestone intraclástico, dolomito arenoso e pseudomorfos evaporíticos; e superior, composto por dolomito fino, dolograinstone oolítico, chert, arenito dolomítico, arenito fino a médio e pelitos. O limite entre os membros é caracterizado como transicional, destacado pela gradativa contribuição de material siliciclástico nos depósitos do membro superior.

Análise de fácie sedimentar A análise de fácies sedimentares resultou na identificação de 12 litofácies, compondo 6 fácies carbonáticas, 2 mistas (carbonatos e siliciclásticos) e 4 siliciclásticas (Tab. 1, Figs. 3 e 4). As fácies são distribuídas em duas associações determinadas como planícies de maré/sabkha (AF1), representantes do membro inferior, e planície de maré mista (AF2) para o membro superior. As duas associações de fácies são compostas por ciclos de perimaré diferenciados (Tab. 2).

Os ciclos de perimaré da associação AF1 são caracterizados por depósitos de sabkha no topo da associação de fácies e pela composição predominante de rochas carbonáticas, com contribuição mínima de material siliciclástico disperso no arcabouço carbonático. $\mathrm{Na}$ associação AF2 do membro superior, os ciclos de perimaré apresentam maior contribuição de material siliciclástico, formando camadas de arenitos e pelitos, e não contém depósitos de sabkha.

PLANÍCIE DE MARÉ/SABKHA (AFl) Esta associação de fácies apresenta camadas tabulares lateralmente contínuas por dezenas de metros constituídas por dolomito fino e dolopackstone/wackestone intraclástico, doloboundstone microbiano, dolomito arenoso e moldes evaporíticos (Figs. 3 e 6A). As camadas formam ciclos que variam de 2 a $6 \mathrm{~m}$ de espessura, com contatos planares bruscos entre si. A base dos ciclos é constituída por dolomito fino com acamamento maciço e laminação plano-paralela incipiente (Dm). O tamanho dos cristais do dolomito fino varia de 12 a $30 \mu \mathrm{m}$ (Fig. 6B) e o dolomito fino maciço é recoberto por camadas de dolopackstone intraclástico (fácies dolopackastone intraclástico com acamamento de megaripples - Dmr), de cristalinidade fina a grossa, com curled flakes e intraclastos tabulares até $5 \mathrm{~cm}$ de comprimento de dolomito fino (tipo rip-up clast) e grãos de quartzo, feldspatos e mica (Fig. 6C). Estas camadas apresentam acamamento de megaripples recoberto por delgadas camadas de dolomito fino ondulado. A laminação interna das megaripples é interrompida por pseudomorfos evaporíticos de sílex na forma de nódulos dispersos.

Nos últimos seis ciclos do membro inferior ocorre concentração de acamamento eneolítico (De), formado por camadas intercaladas de dolomito arenoso e dolomito fino, associadas a estruturas de injeção ou diapiros que dobram e/ou rompem as camadas enterolíticas (Figs. 3 e 6D). Entre os acamamentos há pseudomorfos evaporíticos de sílex na forma de nódulos com textura chicken-wire. Arranjos do tipo sand patch fabric também são identificados pela presença de intercalações irregulares de dolomitos arenosos na forma de lentes delgadas, preenchendo depressões no topo do acamamento enterolítico. Níveis estromatolíticos parcialmente silicificados (Det), medindo até $2 \mathrm{~m}$ de espessura, são encontrados entre as fácies De e Dmr, caracterizados como estratiformes com laminações irregulares e raros domos interligados, localmente exibindo porosidade fenestral (Figs. 3 e 6E).

Os ciclos observados na AF1 são interpretados como sucessões de raseamento e salinidade ascendentes (shallowing and brining upward), individualizados por três subambientes: inframaré (Dm), intermaré (Dmr e Det) e supramaré/sabkha (De, dolomito com moldes evaporíticos - Dev). A partir dos subambientes, dois tipos de ciclos de sedimentação são admitidos para a planície de maré/sabkha: ciclos de inframaré/intermaré que ocorrem logo após o contato com a Formação Serra do Quilombo; e ciclos de inframaré/intermaré/sabkha que acontecem principalmente nas porções intermediária e superior do membro inferior (Fig. 3).

O dolomito fino maciço representa precipitação de lama carbonática em ambiente de inframaré de baixa energia, sem influência de ondas, sendo uma área permanentemente submersa ao nível do mar (Shinn 1983, Tucker \& Wright 1990).

A zona de intermaré é dominada pela migração de formas de leito por meio de correntes trativas de fluxo oscilatório de maré, acompanhadas de intervalos de águas paradas, marcados pelo recobrimento das formas pela lama carbonática. A presença de grãos siliciclásticos sugere influxos esporádicos de material terrígeno. Exposições subaéreas são indicadas por curled flakes e intraclastos tabulares delgados oriundos do 
ressecamento e retrabalhamento da lama carbonática (Shinn 1983, James 1984, Tucker \& Wright 1990).

A presença de pseudomorfos evaporíticos caracteriza a zona superior da intermaré. Os moldes de popcorn e nódulos sílex são registros da precipitação de minerais de evaporitos em poças efêmeras, de águas hipersalinas, com temperatura acima de $35^{\circ} \mathrm{C}$ (Milliken 1979, Arbey 1980, Goodall et al. 2000). A intermaré encontra-se entre a linha de maré baixa normal e maré alta e caracteriza-se como um ambiente hidrodinamicamente ativo, submetido a constantes períodos alternados de inundação pela água do mar e exposição subaérea (Tucker \& Wright 1990).

\section{Tabela 1 - Quadro de fácies sedimentares da Formação Nobres}

\begin{tabular}{|c|c|c|c|}
\hline Fácies Sedimentar & Sigla & Descrição & Processo deposicional/diagenético \\
\hline Dolomito fino maciço & $\mathrm{Dm}$ & $\begin{array}{l}\text { Dolomito fino com acamamento maciço e } \\
\text { laminação plana incipiente. }\end{array}$ & $\begin{array}{l}\text { Precipitação química de carbonatos em ambiente de } \\
\text { baixa energia. }\end{array}$ \\
\hline $\begin{array}{l}\text { Dolomito com } \\
\text { moldes evaporíticos }\end{array}$ & Dev & $\begin{array}{l}\text { Dolomito fino com acamamento maciço, } \\
\text { parcialmente silicificado com pseudomorfos } \\
\text { evaporíticos silicificados na forma de nódulos e } \\
\text { popcorn formando níveis delgados irregulares } \\
\text { de até } 2,5 \mathrm{~cm} \text {. }\end{array}$ & $\begin{array}{l}\text { Precipitação química de carbonatos e evaporitos em } \\
\text { ambiente restrito de baixa energia, hipersalino e alta } \\
\text { taxa de evaporação. Posterior processo de silicificação. }\end{array}$ \\
\hline $\begin{array}{l}\text { Dolorudstone com } \\
\text { tepees }\end{array}$ & Dt & $\begin{array}{l}\text { Brecha carbonática, constituída por clastos } \\
\text { poligonais de dolomito, angulosos dispostos na } \\
\text { forma de "V" invertidos ou tepee, cimentados } \\
\text { por quartzo microcristalino. }\end{array}$ & $\begin{array}{l}\text { Precipitação química de carbonato em ambiente raso } \\
\text { e baixa energia associado a períodos de exposição } \\
\text { subaérea com processos de dissecação e expansão } \\
\text { por hidratação, cimentação precoce de carbonato } \\
\text { posteriormente substituído por quartzo. }\end{array}$ \\
\hline
\end{tabular}

Dolomito fino intercalado com dolomito fino com grãos terrígenos formando acamamento

Dolomito fino/ Dolomito arenoso com acamamento enterolítico

algumas vezes, dobras desarmônicas associadas

De a feições de diápiros. Também ocorrem clastos tabulares (rip-up clasts), nódulos na forma de chicken-wire e finas lentes de arenito dolomítico associadas ao topo das camadas enterolíticas (sand patch fabric).
Precipitação química de evaporitos em águas efêmeras e condições hipersalinas e clima árido, deformações plásticas sin-sedimentares em função das mudanças de volume dos minerais evaporíticos e incursões de sedimentos terrígenos durante tempestades. Processo de dolomitização dos evaporitos.

Precipitação química de carbonatos e influxo de grãos terrígenos sob ação de correntes trativas que induz à migração de formas de leite, exposição subaérea parcial das formas de leito com precipitação de evaporitos intrasedimentar e retrabalhamento do leito por fluxo oscilatório. Substituição de evaporitos por quartzo.

Precipitação química de carbonatos em ambiente de alta energia cimentação.

Dolograinstone oolítico

Doo intraclo grosso com ooides, pisoides cimentado por dolomita e quartzo.

Dolomito fino a médio com laminações

Doloboundstone Det microbianas, estromatólitos estratiformes, microbiano Det dômicos e rugosos silicificados, com porosidade fenestral subordinada.

Camadas de pelito com até $5 \mathrm{~m}$ de espessura,

Pelito laminado Pl com laminação plano-paralela ressaltada por delgados níveis de arenitos e siltitos.

Arenito fino a muito fino com matriz dolomítica

Arenito dolomítico $\quad$ e intraclastos tabulares (rip-up clasts). com acamamento de Amr $\begin{aligned} & \text { e intraclastos tabulares (rip-up clasts). } \\
& \text { Apresenta acamamento de megaripples com }\end{aligned}$ megaripples laminações onduladas e plano-paralelas.

Arenito fino com laminação cruzada cavalgante

Acc Camadas tabulares de até $1 \mathrm{~m}$ espessura, com laminação cruzada cavalgante subcrítica.

Arenito fino a médio de camadas tabulares de Arenito médio com laminação cruzada de baixo ângulo

$\mathrm{Al}$
até $2 \mathrm{~m}$ de espessura com laminação cruzada de baixo ângulo e subordinadamente planoparalela.

Arenito fino a muito fino, intercalado com

Arenito/Pelito heterolítico
Precipitação química de carbonato e trapeamento de partículas carbonáticas por atividade microbiana. Silicificação secundária.

Deposição de sedimento a partir de suspensão em ambiente de baixa energia e esporádicos influxos de areia muito fina.

Migração de formas de leito e retrabalhamento do substrato, em ambiente de sedimentação mista (siliciclástica/carbonática).

Deposição subaquosa com alternância de tração e suspensão.

Deposição por meio da ação do fluxo e refluxo gerados por ondas.

Deposição por meio de migração de marcas e suspensão.

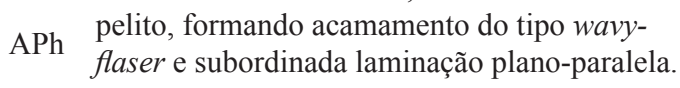
Camadas com até $3 \mathrm{~m}$ de espessura. 
A passagem de intermaré para supramaré/sabkha é marcada por níveis estromatolíticos (Fig. 3). Segundo a classificação de Logan et al. (1964), estes são caracterizados como estromatólitos do tipo LLH, cuja morfologia é estratiforme, com laminações irregulares e onduladas lateralmente contínuas. Os estromatólitos LLH são desenvolvidos em ambientes restritos de baixa energia, com ação mínima de correntes, neste caso caracterizados como poças efêmeras (ponds) presentes na interface intermaré/supramaré e supridas com água marinha durante a maré alta e tempestades.

A planície de sabkha ocorre junto à zona de supramaré, em ambientes costeiros protegidos, com baixo aporte de sedimentos clásticos e alta taxa de
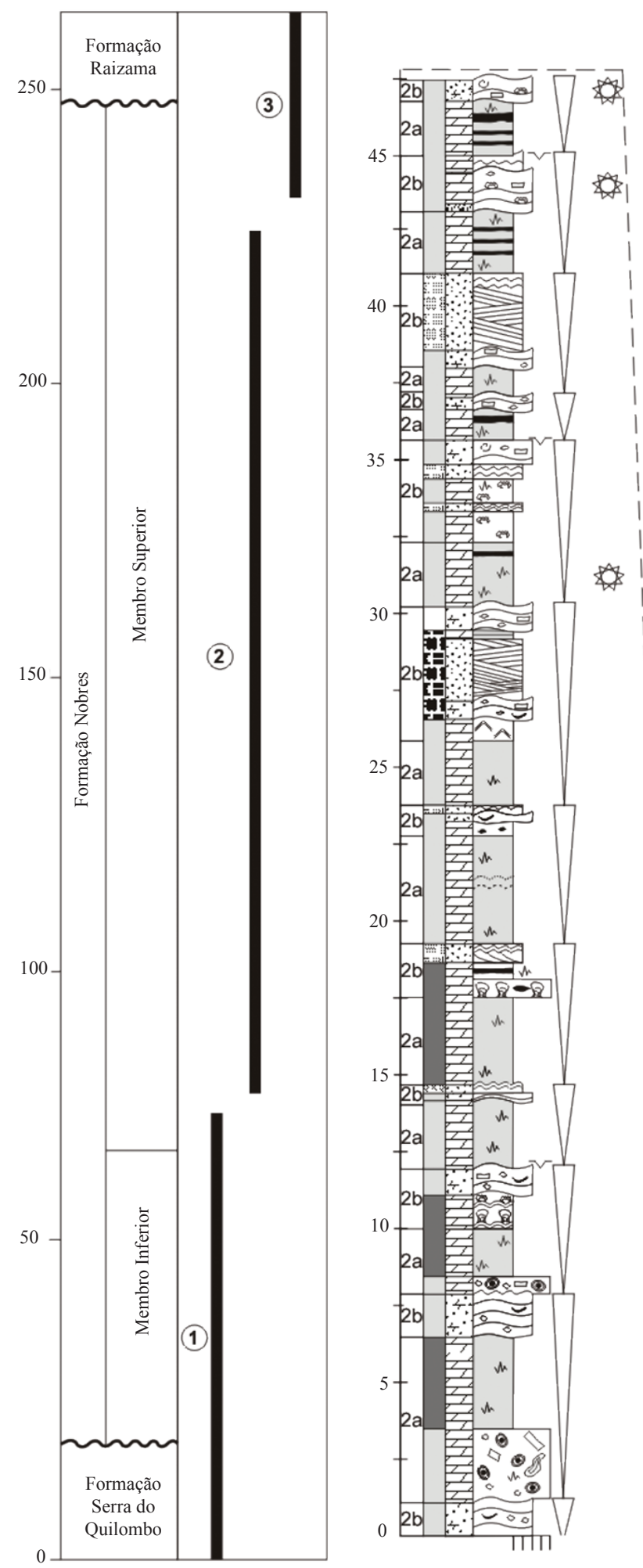

2

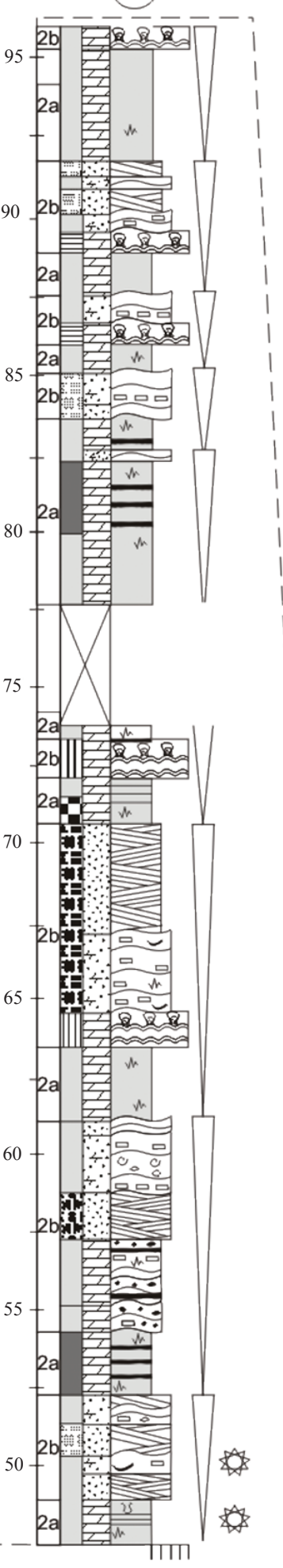

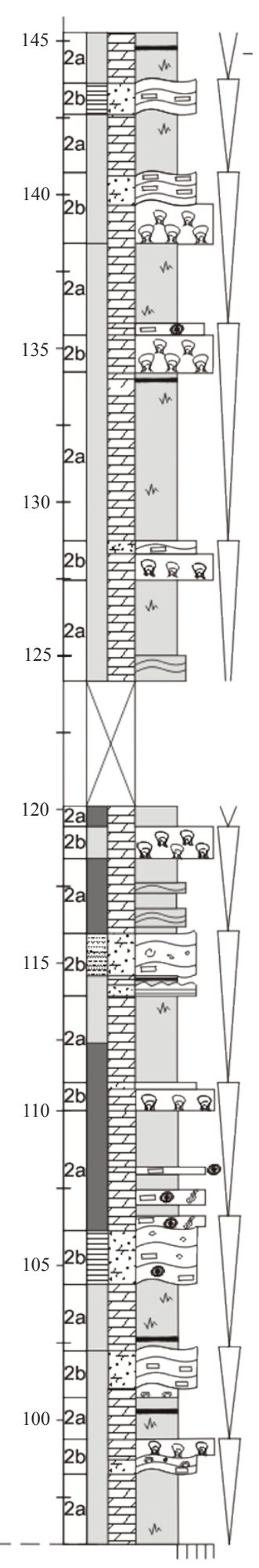

Figura 4 - Perfil estratigráfico da Formação Nobres. Seção 2: km 678 da rodovia BR-070. 
evaporação em clima quente e árido; e esporadicamente inundada por ondas de tempestades (Kendall \& Harwood 1996). As camadas com nódulos de sílex, textura chicken-wire e acamamentos enterolíticos são comuns nestes ambientes (Shinn 1983, Kendall 1992, Tucker 1992, Kendall \& Harwood 1996).

A precipitação de crostas salinas ocorre em lagos e/ou poças rasas efêmeras oriundas de inundações episódicas causadas por tempestades, com contribuição de águas meteórica e marinha. O progressivo processo de evaporação aumenta a salinidade da água, formando salmouras, e proporciona
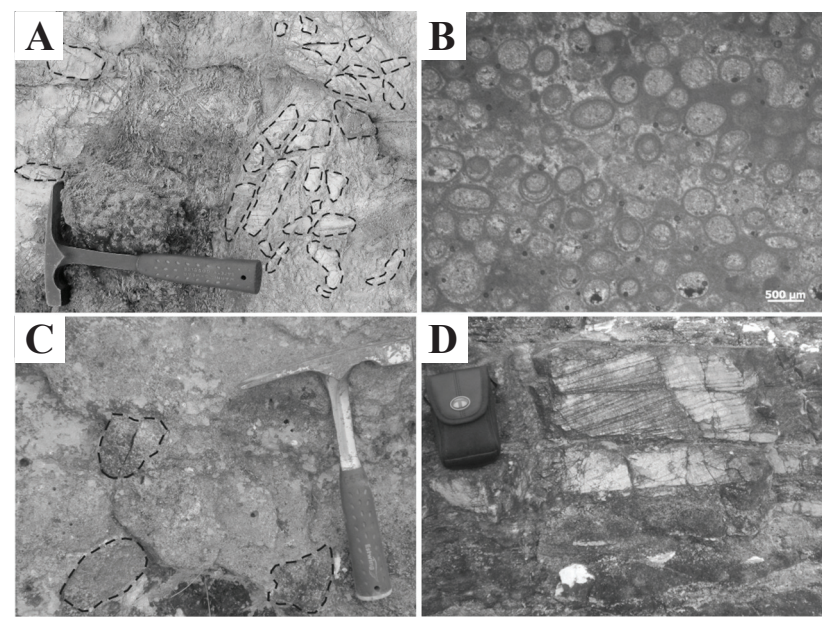

Feições sedimentares dos limites estratigráficos da Formação Nobres Figura 5-(A) Brecha carbonática com matriz do contato inferior da Formação Nobres (clastos de dolomito destacados); (B) Micrografia do dolopackstone oolitico da Formação Serra do Quilombo; (C) Conglomerado do limite erosivo entre as formações Nobres e Raizama; (D) Arenito com estratificação cruzada sigmoidal com mud drapes da Formação Raizama. a precipitação intrasedimentar de evaporitos na zona vadosa.

A mudança do volume entre consecutivas fases de recristalização dos minerais evaporíticos de gipsita-anidrita
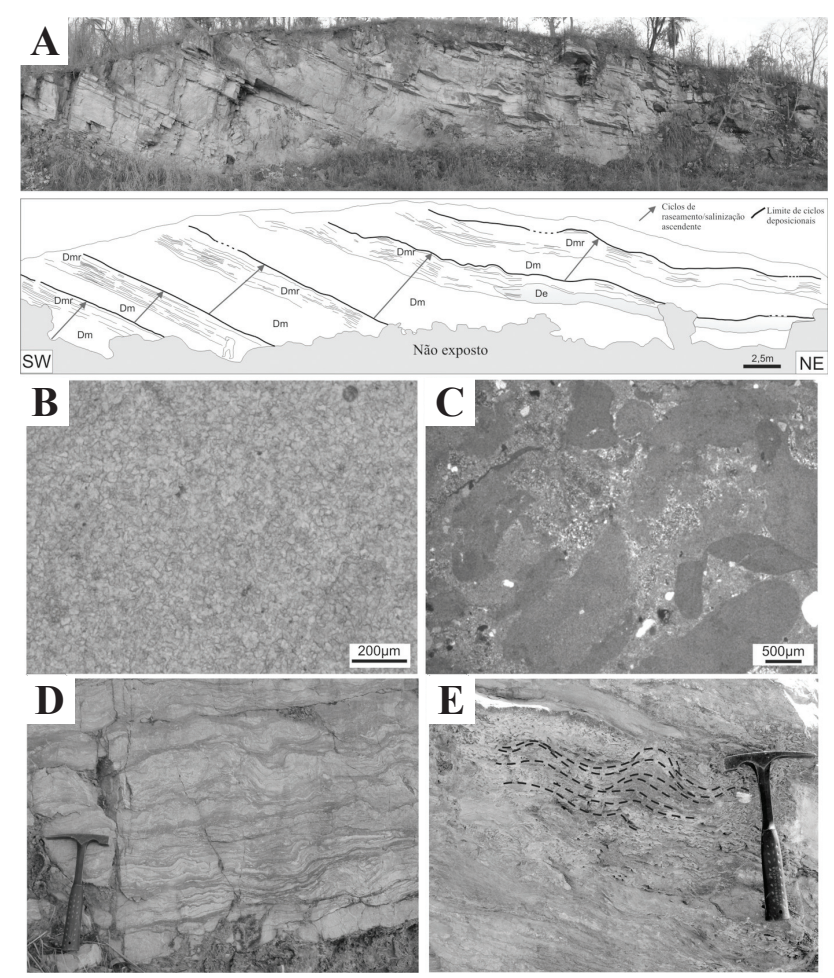

Figura 6 - (A) Seção geológica panorâmica da pedreira Emal-Camil. Ciclos compostos por dolomito fino maciço (Dm), dolopackstone com acamamento de megaripples (Dmr) e dolomito fino com acamamento eneolítico (De) indicando raseamento e salinicade crescente ascendentes; (B) Aspecto textural petrográfico do dolomito fino maciço (Dm); (C) Dolopackstone com intraclasto de dolomito fino (Dmr); (D) Dolomito fino com acamamento enterolítico; (E) Estromatólito estratiforme com raros domos.

Tabela 2 - Quadro das associações de fácies da Formação Nobres

\begin{tabular}{|c|c|c|c|}
\hline Associação/membro & Fácies Sedimentares & Descrição & Interpretação \\
\hline AF1 (membro inferior) & Dm, Dmr, De, Det, Dev & $\begin{array}{l}\text { Ciclos de raseamente e salinidade ascendente de } \\
\text { perimaré de até } 6 \mathrm{~m} \text { de espessura, distribuídos em } \\
\text { camadas tabulares compostas por dolomito fino maciço, } \\
\text { dolopackstone com acamamento de megaripples, } \\
\text { estromatólito estratiforme, moldes evaporíticos e } \\
\text { dolomito fino com acamamento enterolítico. }\end{array}$ & Planície de maré/sabkha \\
\hline AF2 (membro superior) & $\begin{array}{l}\text { Dm, Doo, Det, Dev, Dt, } \\
\text { Amr, Pl, Acc, Al, APh }\end{array}$ & $\begin{array}{l}\text { Ciclos de raseamente ascendente de perimaré com } \\
\text { maior contribuição de sedimentação siliciclástica } \\
\text { de até } 8 \mathrm{~m} \text { de espessura, distribuídos em camadas } \\
\text { tabulares compostas por: dolomito fino maciço, } \\
\text { arenito dolomítico com acamamento de megaripples, } \\
\text { estromatólito dômico e rugoso (tipo cerebroide), } \\
\text { moldes evaporíticos, arenito com laminações cruzada } \\
\text { cavalgante e de baixo ângulo, e pelito laminado. }\end{array}$ & Planície de maré mista \\
\hline
\end{tabular}

Dm: dolomito fino maciço; Dmr: dolopackstone com acamamento de megaripples; De: Dolomito fino/Dolomito arenoso com acamamento eneolítico; Det: doloboundstone microbiano; Dev: dolomito com moldes evaporíticos; Doo: dolograinstone oolítico; Dt: dolorudstone com tepees; Amr: arenito dolomítico com acamamento de megaripples; Pl: Pelito laminado; Acc: arenito fino com laminação cruzada cavalgante; Al: arenito médio com laminação cruzada de baixo ângulo; APh: arenito/pelito heterolítico. 
e anidrita-gipsita resulta no acamamento enterolítico e estrutura tipo chiken-wire (Kinsman 1966, Warren \& Kendall 1985). Este processo causa pressão lateral, contorcendo as crostas salinas em dobras do acamamento enterolítico, além de gerar rompimento de camadas, formando diápiros (Castens-Seidell 1984, Hardie \& Shinn 1986). Eventos de inundação na zona de supramaré geram dissolução parcial dos evaporitos, cuja superfície irregular é preenchida por sedimentos arenosos, formando um arcabouço tipo sand patch fabric (Kendall 1992).
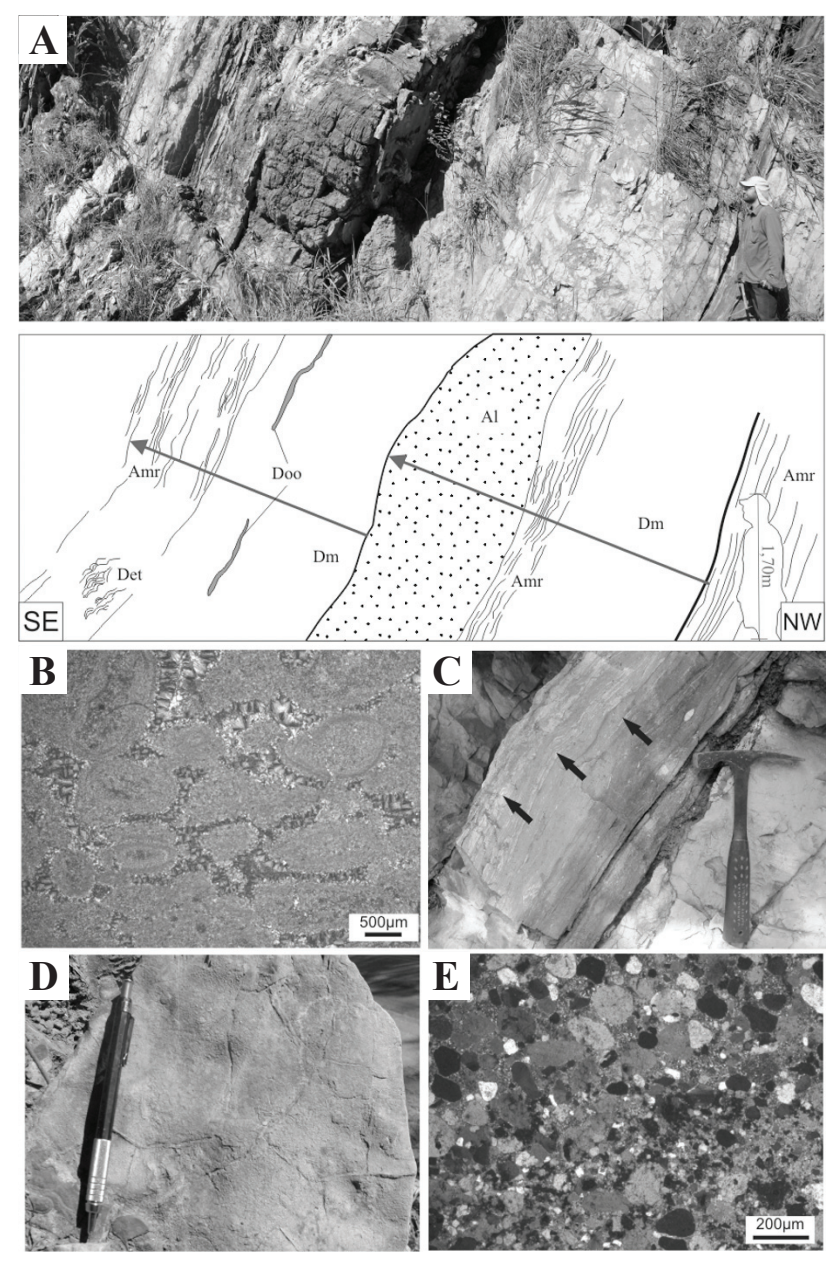

Figura 7 - (A) Fácies da associação AF2, afloramento da Rodovia BR-070 km 678, ciclos de raseamento ascendente compostos por dolomito fino maciço (Dm), dolograinstone oolitico maciço (Doo), doloboundstone microbiano (Det), arenito dolomítico com acamamento de megaripples (Amr) e arenito com laminação cruzada de baixo ângulo (Al); (B) Grãos de oóides parcialmente deformados da fácies Doo; (C) Fácies Amr com finas intercalações de lamito carbonático recobrem a laminação ondulada, conforme a seta indicada na figura; (D) Marcas onduladas de interferência com gretas de dissecação no topo da fácies Amr; (E) Fotomicrografia de arenito dolomítico, com intraclastos de dolomito fino, além de grãos siliciclásticos fácies Amr (polarizadores cruzados).
PLANÍCIE DE MARÉ ÁRIDA MISTA (AF2)

A associação AF2 também é representada por ciclos de espessura métrica, de 1,5 a $8 \mathrm{~m}$, formados por camadas tabulares intercaladas de dolomito fino, dolograinstones oolítico, doloboundstone microbial silicificado, arenito dolomítico, arenito fino a médio, pelito e níveis de evaporitos (Fig. 7A).

A base dos ciclos conta com dolomito fino com acamamento maciço e laminação ondulada incipiente. Geralmente encontra-se associada a camadas delgadas de dolograinstone oolítico (Doo), composto de oóides e pisoides, intraclastos carbonáticos e, subordinadamente, grãos terrígenos (Fig. 7B). Como feições diagenéticas, ocorrem estilólitos, fenestras e níveis de sílex maciço. Níveis de doloboundstone microbiano (fácie denominada doloboundstone microbiano - Det), de até 1,5 m de espessura, são encontrados na porção intermediária dos ciclos. Os estromatólitos encontram-se parcialmente silicificados, o que ressalta as lâminas microbiais cuja espessura varia de 1 a $2 \mathrm{~mm}$. Duas morfologias de estromatólitos foram observadas: (1) dômico a estratiforme; e (2) rugosas tipo cérebro (Fig. 8). Os estromatólitos dômicos têm padrão ondulatório tridimensional, com morfologia externa de hemisferas com até $10 \mathrm{~cm}$ de diâmetro e $12 \mathrm{~cm}$ de altura e colunas ligadas lateralmente (Fig. 8A). Em geral, estes estromatólitos estão posicionados entre as fácies Dm e arenito dolomítico com acamamento de megaripples (Amr). Os estromatólitos rugosos ocorrem como domos isolados de até $30 \mathrm{~cm}$ de diâmetro, com laminações microbianas recobrindo horizontes brechados com estruturas de tepee (Dt) (Figs. 8B e C).

Arenitos dolomíticos com até $4 \mathrm{~m}$ de espessura apresentam megaripples (Amr) e laminação ondulada interna recoberta por finas intercalações de lamito (acamamento flaser), além de marcas onduladas assimétricas, intraclastos tabulares (rip up clast) dispersos e lâminas constituídas de grãos siliciclásticos (Figs. 4, 7A e C).

Os megaripples podem ser recobertos por drapes de lamito carbonático com gretas de contração (Fig. 7D). Raros moldes de evaporitos ocorrem na forma de nódulos de sílex e popcorn, possivelmente minerais de anidrita e halita, respectivamente (Fig. 8D). Internamente, os moldes evaporíticos são compostos por microquartzo na borda, seguidos por quartzina e mega quartzo no centro (Fig. 8E). A fácies Amr se diferencia da fácies Dmr por apresentar mais de $70 \%$ de grãos siliciclásticos (quartzo, microclina e plagioclásio), além de intraclastos de dolomito fino e matriz dolomítica (Fig. 7E). As camadas de dolomito fino com moldes evaporíticos (Dev) são as mais frequentes para o topo dos ciclos. 
A contribuição de material siliciclástico nos ciclos da AF2 é observada (Figs. 3 e 4): no topo dos ciclos, recobrindo a fácies Amr na forma de camadas de arenito fino com laminação cruzada cavalgante (Acc) e laminação cruzada de baixo ângulo (fácies $\mathrm{Al}$ ) (Fig. 7A); e nos ciclos próximos ao contato da Formação Raizama, compostos predominantemente por pelito laminado $(\mathrm{Pl})$, além de arenitos/pelitos com acamamento heterolítico e laminação wavy (fácies $\mathrm{APh}$ ) e laminação cruzada de baixo-ângulo (fácies Al).

Os ciclos são interpretados como sucessões de raseamento e salinidade ascendente (shallowing and brining upward) relacionadas à progradação da planície de maré (Pratt 1992, Tucker \& Wright 1990), incluindo as zonas de inframaré (fácies Dm e Doo), intermaré mista (fácies Amr, Det, Al e Acc), supramaré (fácies Dt, Det e Dev) e inframaré/ intermaré siliciclástica (fácies $\mathrm{Pl}, \mathrm{APh}$ e $\mathrm{Al}$ ).

A inframare é caracterizada como um ambiente deposicional de baixa energia que permitiu a deposição de lama carbonática representada pelo dolomito fino maciço, enquanto nas áreas mais rasas ocorreu a migração de barras oolíticas em função de correntes trativas moderadas.
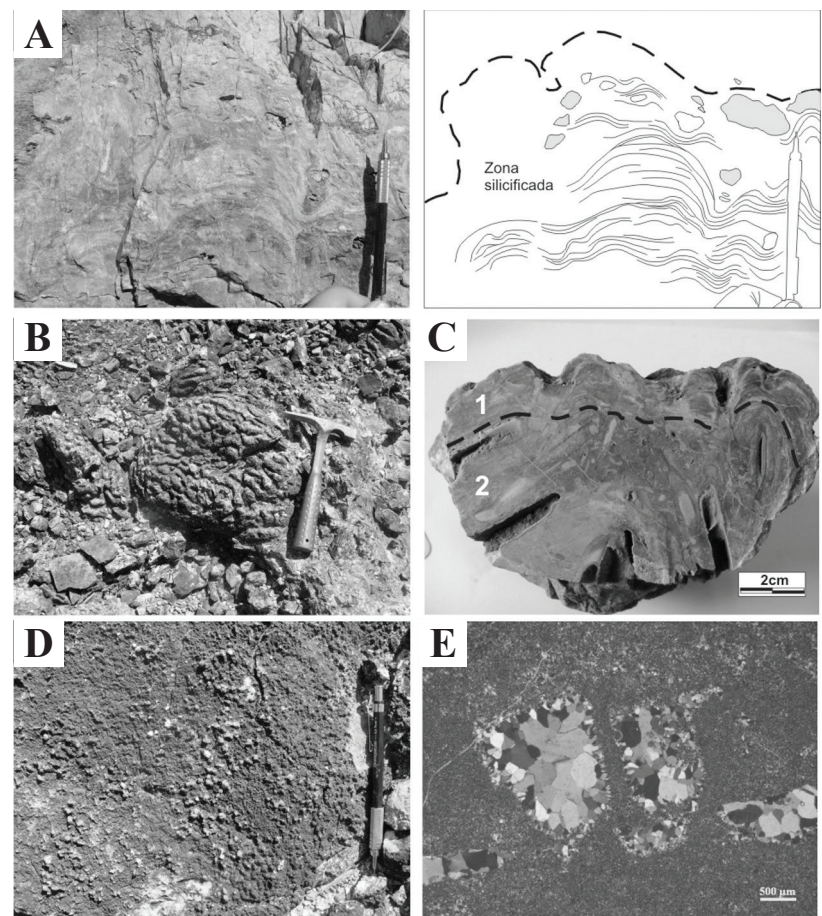

Fácies sedimentares da associação AF2

Figura 8 - (A) Estromatólito estratiforme a dômico com laminações microbianas substituídas por sílica diagenética; (B) Estromatólito rugoso tipo "cérebro"; (C) Laminações microbianas do estromatólito rugoso (1) recobrindo horizonte de brecha com clastos tabulares (2); (D) Moldes evaporíticos na forma de popcorn; (E) Fotomicrografia da textura interna de moldes evaporíticos constituídos de microquartzo, quartzina na borda emega quartzo no centro (polarizadores cruzados).
A sedimentação carbonática foi sucessivamente inibida pelo aumento do influxo de siliciclásticos advindos do continente, levando à deposição de pelitos no ambiente de inframaré. A interface inframaré/intermaré foi colonizada por esteiras microbianas, parcialmente protegidas das correntes, gerando formas estratiformes a dômicas. Areias com megaripples migravam na intermaré e foram recobertas por lamas carbonáticas durante os períodos de maré estofa. Marcas onduladas assimétricas, localmente com padrão de interferência, são atribuídas à migração de pequenas formas de leito induzidas por correntes de maré ou fluxo oscilatório. Períodos de exposição subaérea são marcados pela presença de gretas de contração, tepees, nódulos de sílex e intraclastos geralmente encontrados no limite dos ciclos. Os arenitos que apresentam laminação cruzada de baixo ângulo, marcas onduladas e laminação cruzada cavalgante são relacionados a depósitos praias restritos de intermaré.

Os estromatólitos desenvolvidos sobre tepees e/ou horizontes brechados no ambiente de intermaré superior a supramaré mostram morfologias rugosa ou tipo do cérebro. Os tepees são resultantes da cimentação sinsedimentar e expansão das camadas carbonáticas e/ou evaporíticas superficiais afetadas por um índice de evaporação elevado, que proporciona a elevação do nível do lençol freático e possivelmente percolação de fluídos alcalinos nas zonas vadosas (Demicco \& Hardie 1994, Tucker 2003). O nível cimentado expande pelo crescimento intrasedimentar, fragmentando o arcabouço em moldes poligonais e gerando intraclastos tabulares ou tepees.

MODELO DEPOSICIONAL A Formação Nobres representa depósitos carbonáticos e mistos (carbonáticos/ siliciclásticos) de perimaré, compreendendo depósitos de planície de maré/sabkha e planície de maré mista, influenciados por um clima quente e árido. Estes depósitos ocupam a plataforma carbonática Araras, no sudoeste do Cráton Amazônico durante o Ediacarano (Fig. 9).

$\mathrm{O}$ inicio da deposição do membro inferior da Formação Nobres é marcado pela ocorrência de brecha carbonática de intermaré, posteriormente afogada com a implantação de ciclos de planície de maré/ sabkha (Fig. 9A). A diminuição da hipersalinidade e a maior contribuição de sedimentos siliciclásticos ao longo do tempo levaram ao desaparecimento da planície de sabkha, substituída gradualmente por uma planície de maré mista (Fig. 9B), onde a influência do material siliciclástico desfavoreceu a produção e sedimentação carbonática (Tucker \& Wright 1990). 
O caráter cíclico da sedimentação Nobres sugere o preenchimento sucessivo do espaço de acomodação de, no máximo, uma dezena de metros, o que poderia ter sido gerado pela subsidência tectônica ou variação cíclica do nível do mar. Porém, é difícil explicar a sedimentação cíclica de até $200 \mathrm{~m}$ de espessura apenas pela variação do nível do mar. Desta forma, a tectônica da bacia é considerada o principal motivo da criação recorrente do espaço de acomodação semelhante ao encontrado na sucessão sedimentar dos Pireneus (Bosence et al. 2009). Para explicar a sucessão espessa de ciclos superpostos, admite-se que toda a geração de espaço criada foi rapidamente preenchida pela produção de carbonato que, durante o Neoproterozoico, era controlada por comunidades de estromatólitos desenvolvidas em extensas áreas de planície de maré, o que induzia à precipitação de carbonato in situ e lama carbonática nas áreas adjacentes (Grotzinger 1989, Grotzinger \& Knoll 1999). O sucessivo maciço influxo de siliciclástico apresenta relação direta com o processo de soerguimento da Bacia Paraguai, provavelmente ligado ao início do fechamento do Oceano Clymene, durante a colisão Pampeana-Araguaia no limite Neoproterozoico-Cambriano (Tohver et al. 2010).

CONCLUSÕES A sucessão carbonática da Formação Nobres foi subdividida em: membro inferior,
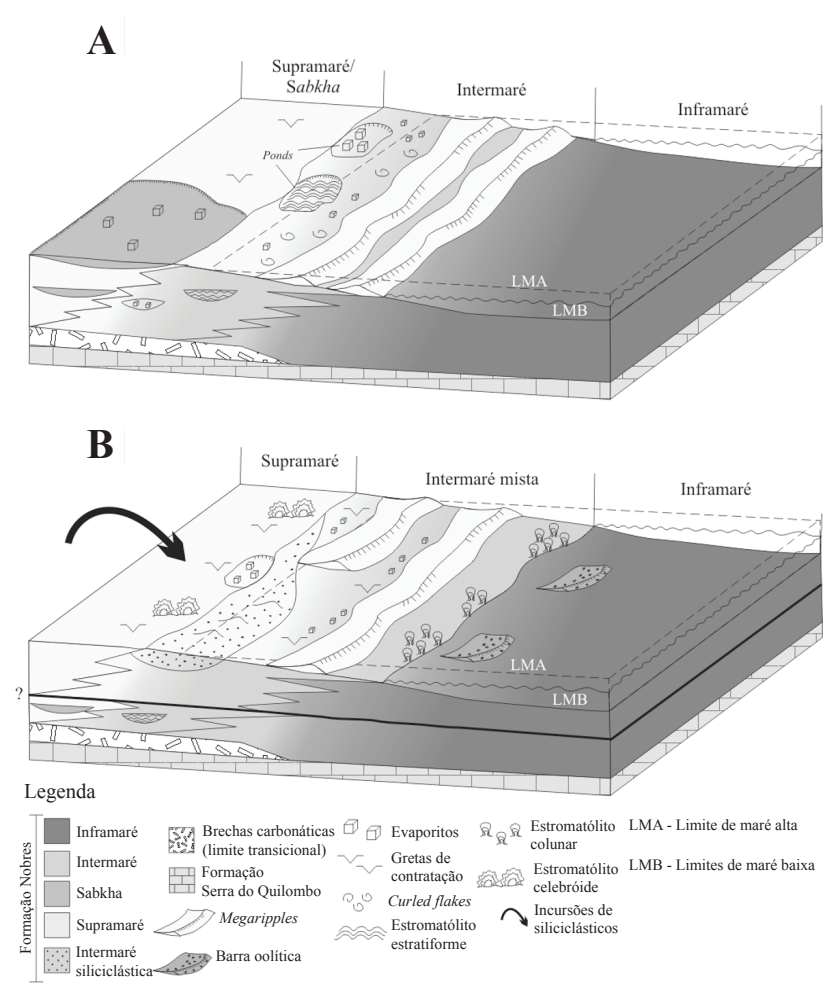

Sistema de sedimentação da Formação Nobres

Figura 9 - (A) Membro inferior, planicie de marél sabkha; (B) Membro superior planície de maré mista. constituído por dolomito fino, dolopackstone/wackestone intraclástico, dolomito arenoso, estromatólitos e moldes evaporíticos; e membro superior, composto por dolomito fino, dolograinstone oolítico, estromatólitos, arenito dolomítico, arenito fino a médio e pelitos. Dolomitização e silicificação afetaram grande parte dos depósitos. A análise de fácies determina dois ambientes deposicionais para a Formação Nobres: (a) planície de maré/sabkha, que representa o membro inferior; passando para (b) planície de maré mista do membro superior, ambas influenciadas por um clima árido e quente, com temperatura acima de $35^{\circ} \mathrm{C}$.

A evolução de sedimentação da plataforma Araras no final do Neoproterozoico indica a progadação do ambiente de planície de maré/sabkha da Formação Nobres sobre o sistema de shorface influenciado por tempestades da Formação Serra do Quilombo. Posteriormente, com a diminuição da hipersalinidade e o maior aporte de siliciclásticos, foi estabelecido o sistema de planície de maré mista, em que o progressivo e o aumento de material siliciclástico inibiram a sedimentação carbonática. A sedimentação cíclica de perimaré da Formação Nobres foi interrompida com a implantação dos canais incisos estuarinos da Formação Raizama, assim, finalizando a evolução da plataforma carbonática Araras.

O estudo detalhado das exposições da Formação Nobres na região de Cáceres, além refinar a interpretação paleoambiental, permitiu ampliar a compreensão da evolução da sucessão carbonática do Grupo Araras no Ediacarano.

AGRADECIMENTOSAos projetos que deram suporte financeiro, Instituto Nacional de Ciência e Tecnologia da Amazônia, Centro Nacional de Desenvolvimento de Ciência e Tecnologia, Ministério da Ciência e Tecnologia, Fundação Amazônia Paraense de Amparo à Pesquisa — INCT-GEOCIAM (CNPq/MCT/FAPESPA Proc. 573733/2008-2), Fundação de Amparo a Pesquisa de São Paulo (FAPESP, processo 08/55833-9) e Coordenação de Aperfeiçoamento de Pessoal do Ensino Superior (CAPES). Aos Profs. Dr Werner Truckenbrodt, Dr. Thomas Fairchild e Dr. Claudio Riccomini, que contribuíram na elaboração do presente texto. À mina Emal-Camil, pelo apoio logístico e acesso às áreas de trabalho. Ao Programa de Pós-Graduação em Geologia e Geoquímica do Instituto de Geociências da Universidade Federal do Pará. 


\section{Referências}

Adams A.E., Mackenzie W.S., Guilford C. 1984. Atlas of sedimentary rocks under the microscope. Longman, 104p.

Almeida F.F.M. 1964. Geologia do Centro-Oeste matogrossense. Boletim da Divisão de Geologia e Mineralogia. DNPM, 219:1-53.

Almeida F.F.M. 1984. Província Tocantins, setor Sudoeste. In: Almeida F.F.M. \& Hasui Y (coords). O Pré-Cambriano do Brasil. São Paulo, Ed. Blücher, p. 265-281.

Almeida F.F.M. \& Mantovani M.S.M. 1975. Geologia e geocronologia do Granito de São Vicente, Mato Grosso. Anais da Academia Brasileira de Ciências, 47:451-458.

Alvarenga C.J.S., Figueiredo M.F., Babinski M., Pinho F.E.C. 2007. Glacial diamictites of Serra Azul Formation (Ediacaran, Paraguay belt): evidence of the Gaskiers glacial event in Brazil. Journal of South American Earth Sciences, 23:236-241.

Alvarenga C.J.S., Santos R.V., Dantas E.L. 2004. C-O$\mathrm{Sr}$ isotopic stratigraphy of cap carbonates overlying Marinoan-age glacial diamictites in the Paraguay Belt, Brazil. Precambrian Research, 131:1-21.

Alvarenga C.J.S. \& Trompette R.R. 1994. A Faixa Paraguai e sua compartimentação estratigráfica e tectônica. In: Congresso Brasileiro de Geologia, 38. Balneário Camboriú, SBG, v.1, p. 239-240.

Arbey F. 1980. Les forms de la silice et l'identification des évaporites dans les formations silicifiées. Bulletin des Centres de Recherches Exploration-Production ElfAquitaine, 4:309-365.

Babinsky M., Trindade R.I.F, Alvarenga C.J.S, Boggiani P.C., Liu D, Santos R.V. 2006. Geochronological constraints on the Neoproterozoic glaciations in Brazil. In: Snowball Earth 2006, Ascona Proceedings, v. 1, p. 19-20.

Barros A M., Silva R.H. da, Cardoso O.R.F.A., Freire F., Souza Junior J.J. de, Rivetti M., et al.. 1982. Geologia. In: DNPM. Projeto Radambrasil. Folha SD. 21 Cuiabá; geologia, geomorfologia, pedologia, vegetação e uso potencial da terra. Rio de Janeiro, Levantamento de Recursos Naturais, 26, p. 25-192.

Boggiani P.C. 1997. Análise estratigráfica da Bacia Corumbá (Neoproterozóico) - Mato Grosso do Sul. Tese de Doutorado, Instituto de Geociências, Universidade de São Paulo. São Paulo, 181 p.

Bosence D., Procter E., Aurrel M., Kahla A.B., BoudagherFadel M., Casaglia F., et al. 2009. A dominant tectonic signal in high-frequency, peritidal carbonate cycles? A regional analysis of Liassic platforms form western thetys. Journal of Sedimentary Research, 79:389-415.

Castelneau F. 1850. Expedition dans les parties centrales de l'Amérique du Sud. Histoire du Voyage, Paris. Paris: Librairie Editeur, 485 p.

Castens-Seidell B. 1984. The anatomy of a modern marine siliciclastic sabkha in a rift valley setting: North-West Gulf of California tidal flats, Baja California, Mexico. Unpublished Ph.D dissertation, Johns Hopkins University, Baltimore, 386 p.
Demicco R.V. \& Hardie L.A. 1994. Sedimentary structures and early diagenetic features of shallow marine carbonate deposits. Oklahoma, SEPM Atlas of Sedimentary Structures, $265 \mathrm{p}$.

Dunham R.J. 1962. Classification of carbonate rocks according to depositional texture. In: Classification of Carbonate Rocks, Ham W.E. (ed.). Classification of carbonate rocks. Tulsa, AAPG Memoir no 1, p. 108-121.

Evans J.W. 1894. The geology of Mato Grosso (particularly the region drained by the upper Paraguay). Geological Society of London Quartely Journal, 50:85-104.

Figueiredo A.J.A. \& Olivatti O. 1974. O projeto Alto - Guaporé. Goiânia, DNPM/CPRM, Relatório do arquivo técnico da DGM, $\mathrm{n}^{\circ} 2.323,11 \mathrm{v}$.

Goodall T.M., North C.P., Glennie K.W. 2000. Surface and subsurface sedimentary structures produced by salt crusts. Sedimentology, 47:99-118.

Grotzinger J.P. 1989. Facies and evolution of Precambrian carbonate depositional systems: emergence of the modern platform archetype. In: Crevello P.D., Wilson J.L., Sarg J.F., Read F. (eds.) Controls on carbonate platform and basin development. Tulsa, Society of Economic Paleontologists and Mineralogists, Special Publication $n^{\circ} 44$, p. 79-106.

Grotzinger J.P. \& Knoll A.H. 1999. Stromatolites in Precambrian carbonates: evolutionary mileposts or environmental dipsticks? Annual Review of Earth and Planetary Science, 27:313-358.

Halverson G.P., Maloof A.C., Hoffman P.F. 2004. The Marinoan glaciation (Neoproterozoic) in northeast Svalbard. Basin Research, 16:297-324.

Hardie L.A. \& Shinn E.A. 1986. Carbonate depositional environments, Part 3: Tidal flats. Colorado School of Mines Quartely, 81:59-74.

Hennies W.T. 1966. Geologia do Centro-Norte, Mato Grosso. Tese de Doutorado, Instituto Politécnico, Universidade de São Paulo. São Paulo, 65 p.

Hoffman P.F. \& Schrag D.P. 2002. The snowball Earth hypothesis: testing the limits of global change. Terra Nova, 14:129-155.

James N.P. 1984. Shallowing-upward sequences in carbonates. In: Walker r.g. (ed.) Facies models: response to sea level change. Gooscience Canada Reprint Series, p. 1-13.

Kendall A.C. 1992. Evaporites. In: Walker R.G \& James N.P. (eds.) Facies models: Response to sea-level Change. Newfoundland, Geological Association of Canada, p. 375-409.

Kendall A.C. \& Harwood G.M. 1996. Marine evaporites: arid shorelines and basins. In: Reading H.G. (ed.) Sedimentary environments: processes, facies and stratigraphy. Oxford, Blackwell Science, p. 281-324.

Kerans C. \& Tinker S.W. 1997. Sequence stratigraphy and characterization of carbonate reservoirs. Society of Economic Paleontologists and Mineralogists Short Course Notes \#40, 165 p. 
Kinsman D.J.J. 1966. Gypsum and anhydrite of recent age, Trucial Coast, Persian Gulf. In: Demicco R.V \& Hardie L.A. Sedimentary structures and early diagenetic features of shallow marine carbonate deposits. Oklahoma, SEPM Atlas series $\mathrm{n}^{\circ} 1$.

Logan B.W., Rezak R., Ginsburg R.N. 1964. Classification and environmental significance of algal stromatolites. Journal of Geology, 72:68-83.

Milliken K.L. 1979. The silicified evaporite syndrome two aspects os silicification history of former evaporite nodules from southern Kentucky and northern Tennessee. Journal of Sedimentary Petrology, 49:245-256.

Nogueira A.C.R. 2003. A plataforma carbonática Araras no sudoeste do Cráton Amazônico, Mato Grosso: estratigrafia, contexto paleoambiental e correlação com os eventos glaciais do Neoproterozóico. Tese de Doutorado, Universidade de São Paulo, São Paulo, 173 p.

Nogueira A.C.R. \& Riccomini C. 2006. O Grupo Araras (Neoproterozóico) na parte norte da Faixa Paraguai e Sul do Craton Amazônico, Brasil. Revista Brasileira de Geociências, 36(4):623-640.

Nogueira A.C.R., Riccomini C., Sial A.N., Moura C.A.V., Trindade R.I.F., Fairchild T.R. 2007. Carbon and strontium isotope fluctuations and paleoceanographic changes in the late Neoproterozoic Araras carbonates platform, southern Amazon Craton, Brazil. Chemical Geology, 237:168-190.

Pratt B.R. 1992. Tepees in peritidal carbonates: origin via earthquake-induced deformation, with example from the Middle Cambrian of western Canada. Sedimentary Geology, 153:57-64.

Shinn E.A. 1983. Tidal flat environment. In: Scholle P.A., Bebout D.G., Moore C.H. (eds.) Carbonate Depositional Environments. Tulsa, American Association Petroleum Geologist, p. 172-210.

Silva Júnior J.B.C, Nogueira A.C.R., Petri S., Riccomini C., Trindade R.I.F., Sial A.N., et al. 2007. Depósitos litorâneos neoproterozóicos do Grupo Alto Paraguai no sudoeste do Cráton Amazônico, Mato Grosso. Revista Brasileira de Geociências, 37:595-606.

Soares J.L. \& Nogueira A.C.R. 2008. Depósitos carbonáticos de Tangará da Serra (MT): uma nova ocorrência de capa carbonática neoproterozóica no sul do Cráton Amazônico. Revista Brasileira de Geociências, 38(4):715-729.

Tohver E., Trindade R.I.F., Solum J.G., Hall C.M., Riccomini C., Nogueira A.C. 2009. Closing the Clymene ocean and bending a Brasiliano belt: evidence for the Cambrian formation of Gondwana, southeast Amazon craton. Geology, 38:267-270.

Trompette R. 1997. Neoproterozoic ( 600 Ma) aggregation of Western Gondwana: a tentative scenario. Precambrian Research, 82:101-112.

Tucker M.E. 1992. Sedimentary petrology. $2^{\text {nd }}$ ed. Blackwell Scientific Publications. 260 p.

Tucker M.E. 2003. Sedimentary rocks in the field. $3^{\text {rd }}$ ed. Chichester, Wiley, 234 p.

Tucker M.E. \& Wright V.P. 1990. Carbonate Sedimentology. Oxford, Blackwells, 482 p.

Walker R.G. 1992. Facies, facies models and modern stratigraphic concepts. In: Walker r.g. \& james n.J. (eds.) Facies Models: response to sea level changes. St. John's, Geological Association of Canadá, p. 1-14.

Warren I.K. \& Kendall C.G.St.C. 1985. Comparison of sequences formed in marine sabkha (subaerial) and salina (subaqueous) settings-modern and ancient. American Association of Petroleum Geologlsts Bulletin, 69:1013-1023.

Manuscrito ID 21016

Recebido em: 17/03/2011

Aprovado em: 31/07/2012 